\title{
Investigation of Internal Die Drool Phenomenon for Different HDPEs
}

\author{
Jan Musil and Martin Zatloukal \\ Polymer Centre, Faculty of Technology, Tomas Bata University in Zlín, TGM 275, 76272 Zlin, \\ Czech Republic
}

\begin{abstract}
In this work, two different HDPEs were investigated from rheological as well as die drool phenomenon point of view. It has been revealed that long-chain branching and low polymer melt elasticity significantly reduce die drool phenomena at the die exit region.
\end{abstract}

Keywords: Die drool, Extrusion, Shear viscosity, Extensional viscosity.

PACS: 47.50.Ef, 47.50.Gj, 83.50.Jf, 83.50.Uv, 83.60.Wc, 83.80.Sg, 83.85.Cg, 83.85.Rx

\section{INTRODUCTION}

During the extrusion of viscoelastic polymer melts, several unwanted flow phenomena which are not fully understand yet, can occur [1-3]. One of them is so called die drool phenomenon.

Die drool is undesirable spontaneous accumulation of polymer melt at the exit of the extrusion die during melt extrusion of polyolefins, PVC, or filled polymers. In common extrusion processes (film blowing, fiber spinning, film casting, etc.) this phenomenon can significantly decrease the productivity of extrusion line due to unwanted and periodically turn off the line and cleaning extrusion die. Moreover, small amount of accumulated (and usually degradated) material at the die exit region can stick to the extrudate which cause its depreciation.

As shown in [4-9], formation of die drool phenomenon is influenced by several factors like low molecular fractions of the polymer and its structure, volatiles, die swell, die design etc. However, serious research about the die drool phenomenon for HDPE polymers has not been performed yet. For this reason, the main aim of this work is to investigate die drool phenomenon for two different HDPEs having different elasticity and branching level. 


\section{EXPERIMENTAL}

\section{Material Characterization}

Two different types of HDPE polymers (HDPE Tipelin 6300B KEZ, TVK, Hungary, and HDPE Liten FB 29 2961, Chemopetrol, Czech Republic - basic characteristics are summarized in Table 1) were chosen for the experimental research.

TABLE 1. Basic characterization of chosen polymers.

\begin{tabular}{|c|c|c|c|c|c|}
\hline Material & Density $\left(\mathrm{g} . \mathrm{cm}^{-3}\right)$ & $M_{w}\left(\mathrm{~g} \cdot \mathrm{mol}^{-1}\right)$ & $M_{n}\left(\mathrm{~g} \cdot \mathrm{mol}^{-1}\right)$ & $M_{z}\left(\mathrm{~g} \cdot \mathrm{mol}^{-1}\right)$ & $M_{w} / M_{n}$ \\
\hline $\begin{array}{l}\text { HDPE Tipelin } \\
\text { 6300B KEZ }\end{array}$ & 0.950 & 194,450 & 16,695 & 892,350 & 11.65 \\
\hline $\begin{array}{l}\text { HDPE Liten } \\
\text { FB } 292961\end{array}$ & 0.954 & 194,950 & 17,175 & 1,045500 & 11.35 \\
\hline
\end{tabular}

Linear viscoelastic property (complex viscosity $\eta^{*}$ ), and transient normal stress difference $N_{l}$ were measured on Advanced Rheometric Expansion System (ARES 2000) in parallel plate geometry mode. Transient uniaxial extensional viscosity $\eta_{E}$ was determined by SER Universal Testing Platform (SER-HV-A01 model) attached to ARES 2000. All measurements were performed at $190^{\circ} \mathrm{C}$ and they are provided in Figures 1-4. As can be seen, HDPE Liten FB 292961 has higher viscosity and elasticity than HDPE Tipelin 6300B KEZ. Moreover, the HDPE Tipelin 6300B KEZ is slightly branched due to occurrence of extensional strain hardening which is not the case for HDPE Liten FB 292961 which has linear chain structure (compare Figures 3 and 4).

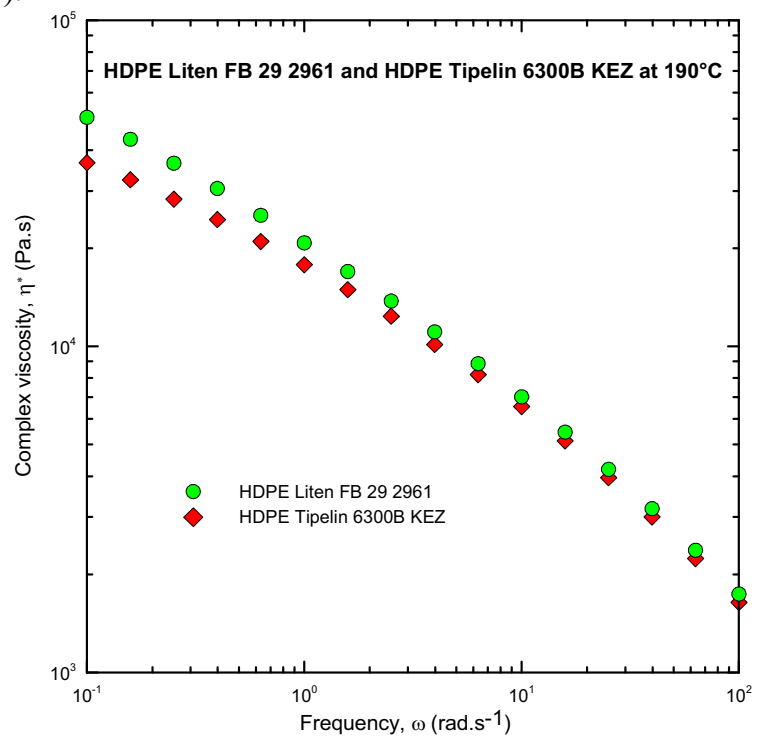

FIGURE 1. Complex viscosity for both investigated HDPEs. 


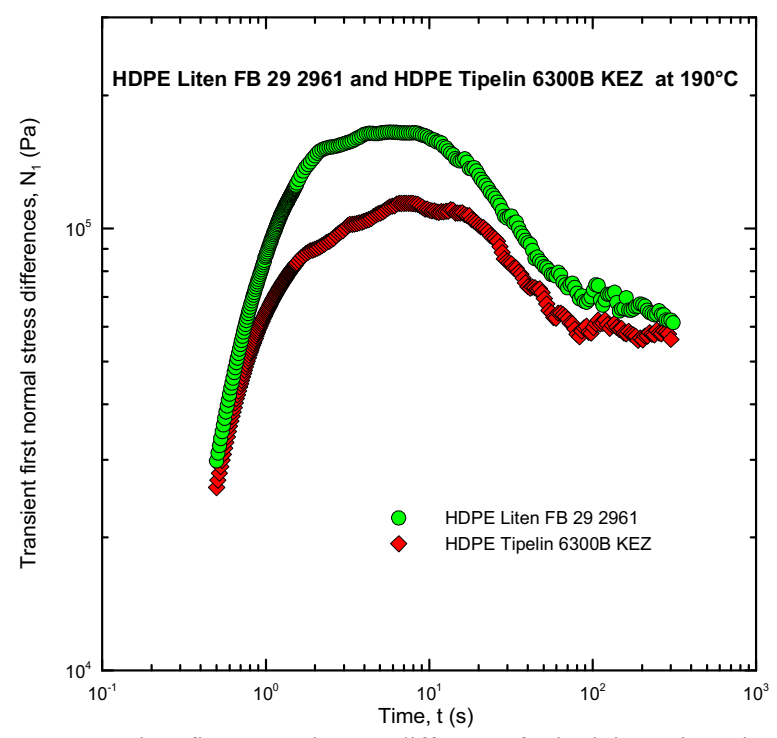

FIGURE 2. Transient first normal stress difference for both investigated HDPEs.

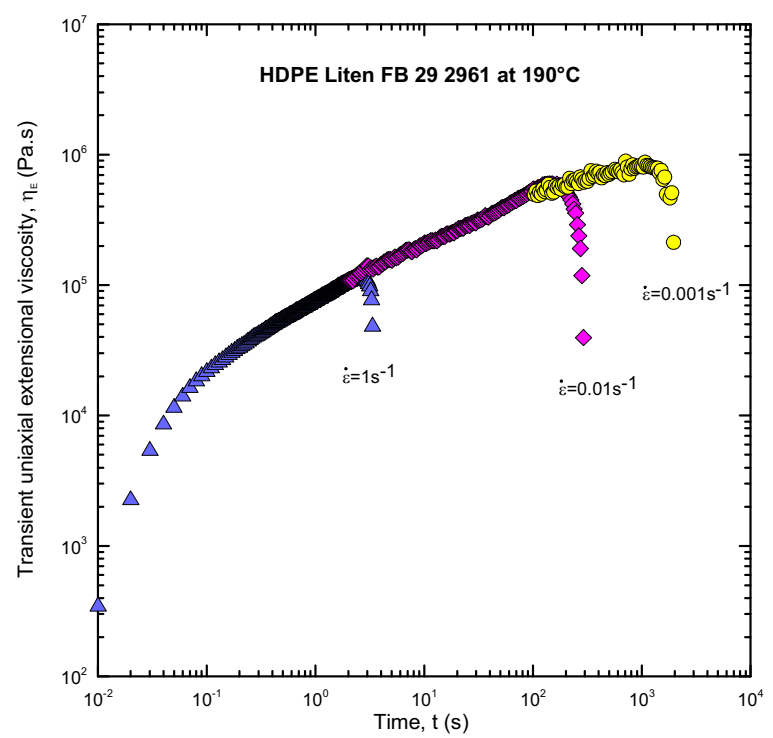

FIGURE 3. Transient uniaxial extensional viscosity for HDPE Liten FB 292961. 


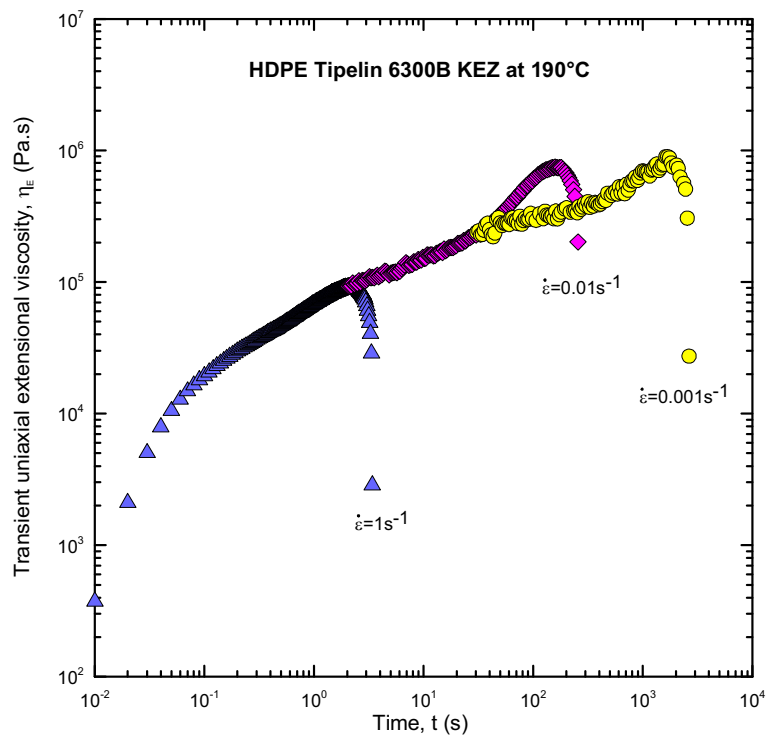

FIGURE 4. Transient uniaxial extensional viscosity for HDPE Tipelin 6300B KEZ.

\section{Die Drool Measurements}

The die drool experiments were performed on a conventional Brabender single-screw extruder with diameter $D=19 \mathrm{~mm}$ and $L=25 D$ which was included in the laboratory extrusion line.

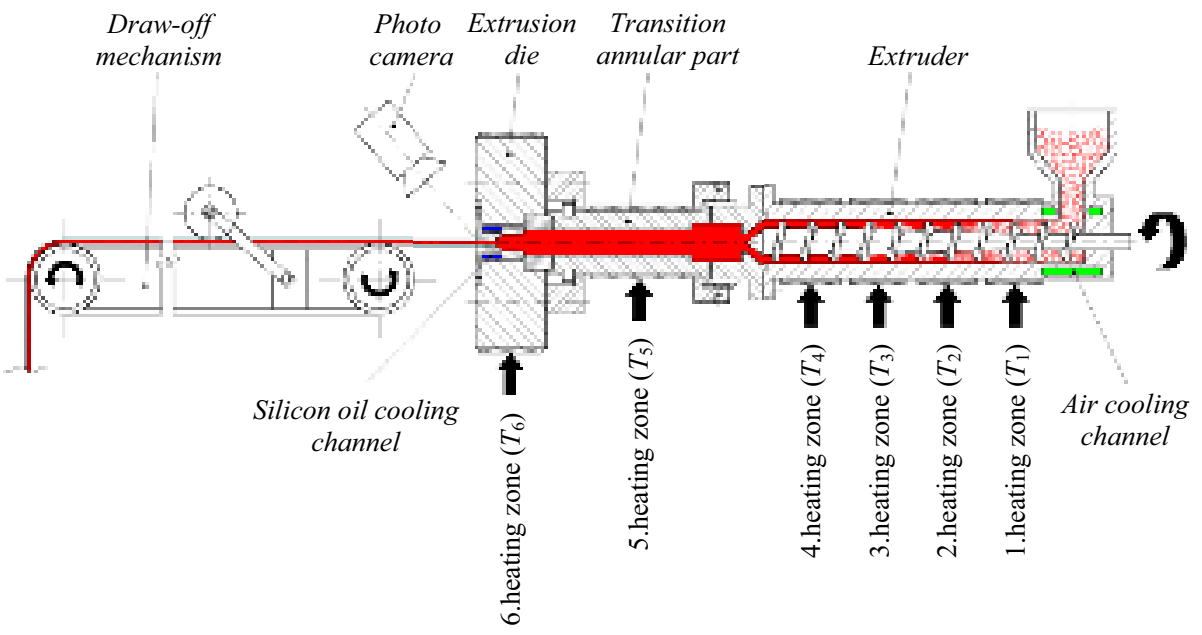

FIGURE 5. Schematic 2D cross-section view of laboratory extrusion line (not in scale). 
The schematic view of laboratory extrusion line is depicted in Figure 5. This line consist of extruder with four heating zones, transition annular part, specially designed extrusion die, which is introduced in [6], photo camera placed near the die exit, and draw-off mechanism. In our experiments, the extruder zones were heated on the following temperatures (from the hopper to the die): $T_{1}=80^{\circ} \mathrm{C}, T_{2}=200^{\circ} \mathrm{C}$, $T_{3}=240^{\circ} \mathrm{C}$ and $T_{4}=260^{\circ} \mathrm{C}$. The transition annular part between the end of extruder and also the extrusion die were heated on $T_{5}=150^{\circ} \mathrm{C}$, and $T_{6}=150^{\circ} \mathrm{C}$, respectively. All experiments were performed as 60 minutes tests and evaluation of the die drool growing was perform by the help of images which were taken after 30s (first 15 minutes), after $1 \mathrm{~min}$ (another 15 minutes) and $5 \mathrm{~min}$ (last $30 \mathrm{~min}$ ). Furthermore, to ensure the reproducibility of the measurements we have perfectly cleaned the barrel, screw and all parts of the die before each experiment. After the each experiment, all images were calibrated in Didger ${ }^{\mathrm{TM}}$ software by the use of six points and the die drool amount was evaluated through the area of accumulated material at the die face, which is in direct relationship with the weight. The time evolution of die drool phenomenon for both tested HDPE samples, at the identical processing conditions described above, is depicted in Figure 6.
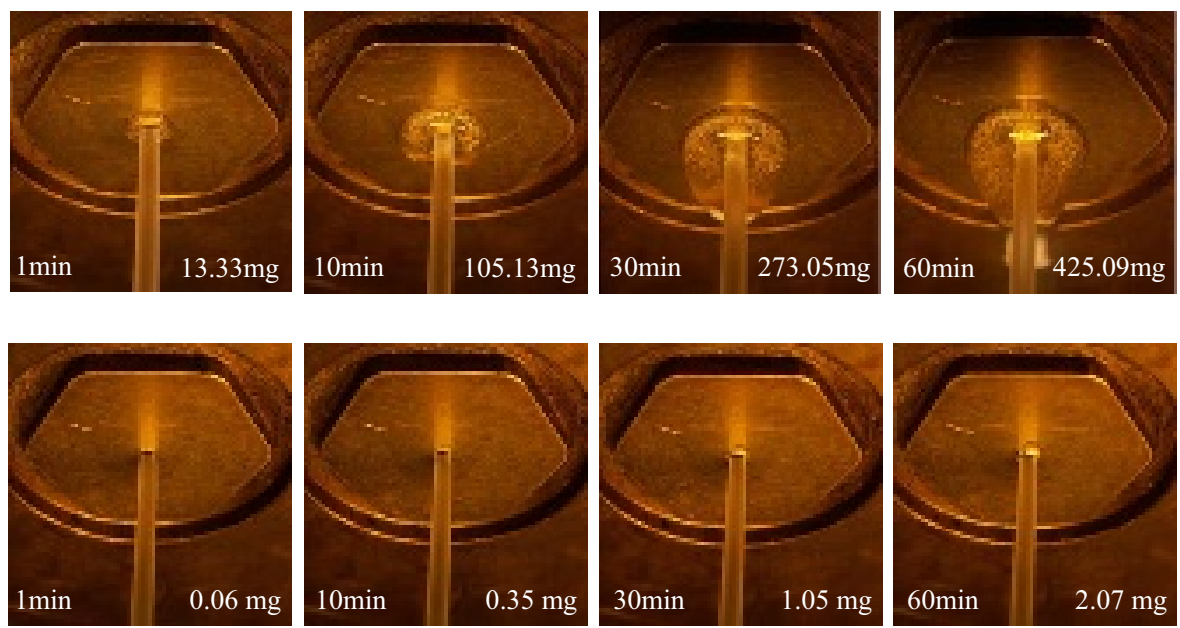

FIGURE 6. Die drool development during extrusion of HDPE Liten FB 292961 (above) and HDPE Tipelin 6300B KEZ (below).

It is clearly seen, that more viscous, more elastic and linear HDPE Liten FB 29 2961 generates much higher level of die drool phenomenon in contrary to less viscous, less elastic and branched HDPE Tipelin 6300B KEZ.

\section{CONCLUSION}

It has been revealed that increase in chain branching of HDPEs and decrease in their elasticity $\left(N_{l}\right)$ and shear viscosity significantly reduces die drool phenomena during extrusion process. 


\section{ACKNOWLEDGMENTS}

The support of the project by the Ministry of Education CR (KONTAKT ME08090) is gratefully acknowledged.

\section{REFERENCES}

1. R. B. Bird, R. C. Armstrong and O. Hassager, Dynamics of Polymer Liquids Vol. 1, New York: Wiley, 1997.

2. R. I. Tanner, Engineering Rheology, Oxford: Clarendon, 1985.

3. S. V. Hatzikiriakos and K. B. Migler, Polymer Processing Instabilities: Control and Understanding, New York: Marcel Dekker, 2005.

4. J. D. Gander and J. Giacomin, Polym. Eng. Sci. 37, 1113-1126 (1997).

5. F. Ding, L. Zhao, A.J. Giacomin and J. D. Gander, Polym. Eng. Sci. 40, 2113-2123 (2000).

6. K. Chaloupková and M. Zatloukal, Polym. Eng. Sci. 47, 871-881 (2007).

7. K. Chaloupková and M. Zatloukal, Polym. Eng. Sci. 111, 1728-1737(2009).

8. T. A. Hogan, P. Walia and B. C. Dems, Polym. Eng. Sci. 49, 333-343 (2009).

9. P. K. Dhori, R. S. Jeyaseelan, A. J. Giacomin and J. C. Slattery, J. Non-Newtonian Fluid Mech. 71, 231-243 (1997). 
Copyright of AIP Conference Proceedings is the property of American Institute of Physics and its content may not be copied or emailed to multiple sites or posted to a listserv without the copyright holder's express written permission. However, users may print, download, or email articles for individual use. 